\title{
Personality and Heart Rate Variability: Exploring Pathways from Personality to Cardiac Coherence and Health
}

\author{
Ada H. Zohar ${ }^{1}$, C. Robert Cloninger ${ }^{2}$, Rollin McCraty ${ }^{3}$ \\ ${ }^{1}$ Psychology, Ruppin Academic Center, Emek Hefer, Israel \\ ${ }^{2}$ Psychiatry, Washington University School of Medicine, St. Louis, USA \\ ${ }^{3}$ Institute of Heartmath, Boulder Creek, USA \\ Email: adaz@ruppin.ac.il, crcloninger@gmail.com,rollin@heartmath.org
}

Received October 2013

\begin{abstract}
Background: Personality and heart rate variability (HRV) are each strong predictors of well-being, particularly cardiac health and longevity. The current project explores the correlates of personality traits on heart rate variability (HRV) to clarify how autonomic regulation may mediate the development and maintenance of health and disease. Hypothesis: Personality traits will be significantly correlated with specific measures of HRV. In particular, the Character traits of Self-Directedness, Cooperativeness, and Selftranscendence are known to promote physical, mental, and social aspects of well-being, so they were expected to be associated with indices of HRV indicating autonomic balance. Methods: Participants were 271 volunteers from the community, adult men and women. They received an extensive self-report questionnaire, allowing for a comprehensive personality evaluation. Of these participants, 118 underwent ambulatory-24 hours recording of HRV. The HRV recordings were sent to the Institute of HeartMath for interpretation. Data Analysis: Data for personality was retrieved from the Qualtrics site after online administration, into which the HRV data were entered. Analyses were conducted in SPSS 20. Results: Systematic and significant associations between personality traits were found. In particular, the Temperament and Character Inventory's character traits were related to autonomic balance as measured by the ratio of low frequency (sympathetic) to high frequency (parasympathetic) activity. Openness, aggression, avoidant attachment, and forgiveness were found to relate to several HRV variables. Conclusion: The relations among personality and HRV support the validity of the measures in ways that clarify the strong relations among personality, HRV, and health. Further work to replicate and extend these preliminary findings in a larger sample is underway.
\end{abstract}

Keywords: TCI; HRV; Openness; Forgiveness; Personality; Health

\section{Introduction}

\section{Personality Measures and Health}

There is a strong link between personality and health-physical health in general and cardiac health in particular. Personality influences health via several active pathways. There is a relationship between personality and adopting a healthy lifestyle (HLS). For example, personality influences the probability of smoking (Zohar \& Cloninger, 2011), of eating a healthy diet (van de Bree, Przybeck, \& Cloninger, 2006), of exercising (Raynor \& Levine, 2009), and of seeking appropriate and timely medical attention. Personality has considerable influence on adopting an HLS, and HLS is an obvious pathway to health. However, HLS does not fully explain the covariance of personality and health, demonstrating that there are additional pathways (Edmonds, 2011).

Personality influences the perception of stress by an individual both in everyday social interactions (Uliaszek et al., 2012) and when faced with major life challenges (van Zuidena et al., 2011). In particular childhood adversity seems to exercise an enduring effect on health and vitality that affects individuals even into old age (Surtees et al., 2011). Stress, and especially emotional stress, has been shown to pave multiple routes to ill-health: by affecting the immune system, the hypothalamicpituitary-adrenal (HPA) axis, chronically increased levels of serum cortisol, and by way of chronic hyperactivity of the sympathetic nervous system (SNS) (Miller, Chen, \& Parker, 2011). Childhood adversity, such as neglect or abuse, is also associated with impaired character development (Josefsson et al., 2013b), insecure attachment (Kwako et al. 2013), and aggression (Hiramura et al., 2011) as well as epigenetically altering the function of the immune system (Cole et al., 2010).

The manner in which personality is defined and measured affects the research results on links between personality and health. The empirically derived big five factor (BF) personality traits of low Neuroticism and high Conscientiousness have been linked to adaptive health behavior (Lodi-Smith et al., 2011), cardiac health (Chapman \& Goldberg, 2011), and longevity (Chapman, Fiscella, Kawachi, \& Duberstein, 2010). The theoretically derived temperament and character bio-psychosocial model of personality, measured by the Temperament and Character Inventory (TCI) has been associated with increased risk for psychiatric disorders (Cloninger, Zohar, Hirschmann, \& Dahan, 2012), response to a wide range of psychiatric and other medical interventions, and cardiac risk factors (Hintsanen et al., 2009) (Rosenstrom et al., 2012). The BF and TCI traits can also be dichotomized to above and below the median, and combined to form multidimensional personality profiles associated with health and well-being (Cloninger \& Zohar, 2011; Rosenstrom et al., 2012). 
Personality can affect autonomic function and dynamics. Increased neuroticism is linked to increased SNS activation, as measured by increased electro-dermal response, as well as increased anticipatory anxiety (Drabant et al., 2011). Individual differences in the BF personality traits are linked to individual differences in electrocardiogram (ECG) amplitude patterns, in particular high Neuroticism and low positive emotion (Koelsch, Enge, \& Jentschke, 2012).

\section{Heart Rate Variability}

Heart rate variability (HRV) is measured by the variability of beat-to-beat intervals, and is an indicator of health and wellbeing in the general population (Antelmi et al., 2004). High HRV is associated with reduced medical morbidity and increased longevity (Matsuoka et al., 2005), and higher cognitive functioning. Low HRV is a predictor of risk for myocardial infarct (MI), and sudden cardiac death, and all-cause mortality while high HRV is a predictor of recovery from MI (Carney et al., 2001; Ablonskytè-Dūdonienè et al., 2012). Consequently differences between people in HRV strongly predict their rates of morbidity and mortality, including both physical and psychological aspects of health (Araujo et al., 2006).

Variation in HR results mainly from physical exertion (Grant, Vilijoen, van Rensburg, \& Wood, 2012) but also from responses to internal and external stimuli, especially novel stimuli that may be interpreted as threatening (Thayer, Ahs, Fredriksen, Sollers III, \& Wager, 2012). While the heart provides a relatively steady underlying rhythm, this rhythm is affected by the slowing (inhibitory) influence of the parasympathetic nervous system (PNS) and the accelerating (excitatory) effect of the sympathetic nervous system (SNS). The average heart rate of 70 - 80 reflects a relative balance between the action of the two components of the autonomic nervous system (ANS), the PNS and the SNS. In ambulatory recordings the ratio of low to high frequency (LF/HF ratio) is a useful indicator of the relative balance between the activity in the sympathetic and parasympathetic systems. Several measures of different components of heart rate variability can be reliably measured to assess the characteristics and changes of an individuals, autonomic functioning over time (Voss, 2007). For example, HRV is greater in the young, and in the physically fit, and decreases with age (Task Force of European Society of Cardiology et al., 1996; Antelmi et al., 2004).

$\mathrm{HRV}$ is also a finely tuned measure of heart-brain communication, as well as a strong predictor of morbidity and death. We expect that a better understanding of HRV in relation to individual differences in personality and life-style choices will contribute to improved medical diagnosis and treatment. While the average heart rate (HR) is relatively easy to measure over a short time period, its variability can be more challenging to measure reliably (Jarrin et al., 2012). In order to insure high reliability of HRV measurement, 24 hour ambulatory recordings can be made, as was done in the current study, so that the HRV variables are calculated over a long sampling window across the full range of a person's daily activities. The 24-hour ambulatory recording increases the ecological validity of the HRV measurement, and hence its relevance to self-regulatory mechanisms by which personality may mediate and modulate the relationship between HRV and health.

Personality is a way of describing the way a person has learned to adapt to their life circumstances. Temperament traits are moderately stable throughout the life span on average, but character traits continue to develop in response to the demands of life roles and social norms throughout the lifespan (Cloninger, 2003; Josefsson et al., 2013a). Specifically, Self-directedness and Cooperativeness increase as needed to facilitate a person's responsibility for work and social relatedness to about age 45 years. Self-transcendence decreases through age 45 and then later increases again in response to the challenges of ultimate situations like suffering and imminent mortality (Cloninger, 2003; Josefsson et al., 2013a). The maturation of character traits appears to be a way to promote and maintain health by facilitating healthy self-regulation of emotional reactions and lifestyle choices (Cloninger et al., 2010; Cloninger et al., 2012). In particular, higher levels of the character traits of Selfdirectedness, Cooperativeness, and Self-transcendence are all associated with positive emotions, satisfying social relations, and perceived physical health (Cloninger \& Zohar, 2011). Outlooks on life characterized by positive emotions and a sense of connectedness have been shown to promote psychosocial functioning and psychophysiological coherence including increased HRV and improved synchronization in ANS dynamics (Bradley et al., 2010; McCraty et al., 1999).

In prior work we have shown that individual differences in personality influence the physical, mental, and social aspects of health and well-being (Cloninger et al., 2010; Cloninger \& Zohar, 2011). Personality affects the individual's emotional state, autonomic stability, immune response, capacity to selfregulate stress, as well as health behavior and response to medical treatments. The current study undertakes an integrative and comprehensive measurement of personality in order to look for pathways from personality to HRV. Because of its exploratory nature, the study was designed to measure many different personality traits that might contribute to increased HRV and resilience.

\section{Methods}

\section{Personality Measures}

The Temperament and Character Inventory in Hebrew (TCI), is based on a neuropsychological and genetic understanding of brain structure and activity. It measures four temperament scales and three character traits. The Hebrew version has excellent psychometric properties and predictive validity for subjective and objective health (Zohar \& Cloninger, 2011).

DS14 in Hebrew (Zohar, Denollet, Lev-Ari, \& Cloninger, 2011) has 14-items and is made up of two subscales, negative affect (NA) and social inhibition (SI). Posited by Denollet (Denollet, 2005) in the context of cardiac health, it awards a score of Type D to individuals who score 10 and above on both dimensions, and Non D to those who do not.

The Big Five Factor Brief Inventory in Hebrew (BFI44; Etzion \& Lasker, 1998), measures the big five factors of personality: Openness, Agreeableness, Extroversion, as well as Conscientiousness and Neuroticism. The latter two have been found to be highly predictive of HLS, health and longevity. The BFI44 in Hebrew has excellent psychometric properties and has been widely used in research.

Toronto Alexithymia Scale (TAS20, Bagby, Parker, \& Taylor, 1994) measures difficulty in identifying, describing and relating to one's own feelings. This 20 -item scale has excellent psychometric properties in the original English, was translated with permission into Hebrew, and found to have excellent 
structural and predictive validity as well as high scale reliability (Zohar \& Cloninger 2011).

Trait Forgiveness Scale (TFS; Berry, Worthington, O’Connor, Parrott III L., \& Wade, 2005) is a 10-item scale asking about the degree to which individuals are able to forgive and forget rather than carry a grudge. The original scale has excellent psychometric properties; it was translated for the proposed study by a process of translation, independent back-translation, and revision.

Aggression Questionnaire-is a 29-item inventory with excellent psychometric properties in the original English (Buss \& Perry, 1992) as well as in the Hebrew translation (Al-Krenawi, Graham, \& Kanat-Maymon, 2009). It has four subscales: hostility, anger, physical aggression, and verbal aggression.

Meaning in Life Questionnaire (Steger, Frazier, Oishi, \& Kaler, 2006) includes 10 items about interest in finding meaning and attainment of a sense meaning. It has good psychometric qualities in the original, and has been translated and used in research in Hebrew with good results.

Center for Epidemiological Studies Depression Scale (CESD; Radloff, 1977) is a 20-item depression symptom scale, assessing a one-week time frame, designed as a general-population-screener, with an excellent translation into Hebrew.

Authentic Happiness Scale (AHI; Seligman, Steen, Park, \& Peterson, 2005). The AHI is designed to measure changes in happiness over time. It has 24 multiple choice questions that encompass four areas of potential happiness: pleasure, engagement, achievement, and meaning. The original scale has excellent psychometric properties; it was translated for the proposed study by a process of translation, independent back-translation, and revision. The AHI was designed to be sensitive to changes in happiness over time. The CES-D and the AHI scores should be negatively correlated.

Positivity scale (Caprara et al., 2012) is an 8-item inventory of positive evaluations of the self, answered on a 5-category Likert-like response scale that adds explained variance to the BFI model and is independent of the five factors. It was translated (with permission) for the proposed study by a process of translation, independent back-translation, and revision.

The Experiences in Close Relationships Short Scale (ECR; Wei, Russell, Malinckrodt, \& Vogel, 2007), is a 12-item questionnaire designed to assess attachment style in adults. It has anxiety and avoidance subscales, yielding two continuous scores, as well as dividing individuals into 4 types, according to their score vs the median on the two scales. It has been found to be reliable and valid, and highly predictive of emotion and emotion regulation.

\section{HRV Measurement}

HRV was recorded using a First beat Body Guard recorder, a lightweight accurate recorder of HRV with a sample rate of $1000 \mathrm{~Hz}$, which is attached with two snap-on electrodes to the chest, for 24 hours. Originally designed for use during athletic training, it weighs only 24 grams and is small in size, so participants reported that they were able to forget about it and to go about their daily activities as usual. The monitors were connected when the batteries were fully charged, allowing for a margin of time to disconnect and download the recordings. The recording was then uploaded for analysis to the Institute of HeartMath (IHM) in CA. The Autonomic Assessment Report (AAR) issued by IHM after expert manual inspection for ire- gularities included time domain and frequency domain (i.e., power spectral density) variables.

Both the time domain and the frequency domain analyses have advantages and disadvantages. The time domain measures are the simplest to calculate but do not provide as good of a means to quantify the various underlying rhythms in the HRV or autonomic balance. The heart rate (HR) generated by the sinoatrial node in the absence of any neural or hormonal influence is about 100 to 120 beats per minute (Hainsworth, 1995). The HR of a healthy person reflects the net balance between the activity of the parasympathetic (vagal) nerves, which slow it and the sympathetic nerves, which accelerate it. Both the sympathetic and parasympathetic branches of the autonomic nervous system are tonically active in healthy people, but the parasympathetic branch dominates during rest and digestion whereas the sympathetic branch dominates during aggressive or avoidant ("fight or flight") responses to stress or challenge and during physical exercise. The heart responds to parasympathetic stimulation of the sinus node much more quickly than it does to sympathetic stimulation. Thus in the absence of arrhythmias, high frequency (fast) responses indicate parasympathetic activation whereas lower frequency (slow) responses indicate sympathetic activity.

In the time domain the most important measures are heart rate, SDNN, the SDNN Index, and RMS-SD. SDNN is the standard deviation of the time interval between successive normal heart beats (i.e., the RR intervals) in the 24-hour recording, and reflects all influences on HRV including slow influences across the day, circadian variations, the effect of hormonal influences such as cortisol and epinephrine. The SDNN Index is the mean of the standard deviation of all the normal RR intervals for each 5-minute segment of the 24-hour recording, and reflects rhythms operating within a 5-minute segment only. The RMS-SD is the root mean square of the RR intervals (i.e., square root of the mean of the squared differences in time between successive normal heart beats), so it reflects high frequency (fast or parasympathetic) influences on HRV (i.e., those influencing larger changes from one beat to the next).

In the frequency domain analysis, measures of different frequencies of HRV are extracted by Fast Fourier Transforms of the 5-minute segments, thereby excluding the ultra-low frequency (ULF) influences on heart rate related to circadian influences, such as hormonal release, that are measured in analysis of the 24-hour data. The variance (i.e., power) in HRV is measured in three bands of the frequency distribution of the Fourier transforms of the 5-minute segments: Very Low Frequency (VLF, .003 to .04 Hz), Low Frequency (LF, .04 to .15 $\mathrm{Hz}$ ), and High Frequency (HF, .15 to $.40 \mathrm{~Hz}$ ). The power in HF bands reflects fast changes in beat-to-beat variability due to parasympathetic (vagal) activity, whereas that in the VLF band is thought to reflect an intrinsic rhythm produced by the heart which is modulated by primarily by sympathetic activity. The HF band is sometimes called the respiratory band because it corresponds to HRV changes related to the respiratory cycle and can be increased by slow, deep breathing (about 6 or 7 breaths per minute) (Kawachi et al., 1995) and decreased by anticholinergic drugs or vagal blockade (Hainsworth, 1995). The LF band reflects a mixture of sympathetic and parasympathetic activity, but in long-term recordings like ours, it reflects sympathetic activity and can be reduced by the beta-adrenergic antagonist propanolol (McCraty \& Atkinson, 1996). In addi- 
tion to analyzing the 5-minute segments, a spectral analysis is carried out with the entire 24-hour period as one record to extract the ULF (below .003) variability due to circadian influences.

The natural logarithm of the ratio of LF to HF power (Ln $\mathrm{LF} / \mathrm{HF}$ ) is the main indicator of autonomic balance between the sympathetic and parasympathetic systems. When a person is in a state of psychophysiological coherence characterized by a sine wave pattern in the HRV at a frequency of $0.1 \mathrm{Hertz}$, the LF/HF falls greatly because of increased parasympathetic activity and/or decreased sympathetic activity. Psychophysiological coherence is a state of calm alertness that occurs naturally with sustained positive emotions and can be induced by slow, deep breathing. More subtle reductions in this ratio occur with activities that increase efferent parasympathetic activity such as when relaxing, sleeping, or with positive moods states. On the other hand, when a person is stressed, aggressive, or defensive, the $\mathrm{LF} / \mathrm{HF}$ rises due to increased sympathetic activity and/or decreased parasympathetic activity.

\section{Participants}

271 adult community volunteers, men and women, who had participated in a previous study of personality and health which took place between 2006 and 2010 (Zohar \& Cloninger, 2011) completed the online personality self-report. Of these, 118 individuals were also measured for 24-hour HRV. Inclusion criteria were level of Hebrew good enough to self-report on a questionnaire, and mobility (coming to the laboratory for the study). Exclusion criterion was a known heart rate disorder. On analysis, 14 of the participants (11 of them men) turned out to have an unusable recording, mostly due to a (unreported) heart rhythm disorder. Therefore, 104 participants' data were included in the analyses. These participants were 46 to 79 years old (mean 61.4, SD 8.7) of whom $37.5 \%$ were men.

\section{Ethical Review}

The research protocol was reviewed and approved by the Institutional Review Board. Participant's privacy was protected and data safety ensured. No pressure to participate or to continue participation was brought to bear. Participants signed an informed consent form after a discussion of the study with the experimenter, and the experimenter co-signed the form in the participant's presence.

\section{Results}

No significant differences in any personality variables measured at outset (2006-7) $(\mathrm{N}=1102)$ and the current assessment ( $N=104)$ were found. Thus there was no self-selection for participation in the current study based on personality variables that might bias the results.

Our main index of autonomic balance was Ln (LF/HF). We also examined the correlations between all primary HRV variables and a wide range of personality variables. We expected that consideration of several of the HRV variables and personality variables would help to clarify the interpretation of the complex non-linear relationships between personality and autonomic regulation. We found that HRV was related to personality in very specific ways, indicating substantial construct and discriminant validity of both the HRV and the personality variables. We report only on personality variables which had sig- nificant correlations with at least one HRV variable.

Of the TCI traits, all three character traits correlated negatively with $\mathrm{Ln}(\mathrm{LF} / \mathrm{HF})$, indicating that a more mature character development was associated with greater parasympathetic activity (vagal tone) and lower overall sympathetic activity. As the TCI theory predicts that better emotional regulation (and higher HRV) will be related to an overall rise in all three character traits, we also examined Creativity, the product of all three character traits. Creativity is defined here as the synergistic quality arising from the combination of high Self-directedness (i.e., resourceful, realistic), high Cooperativeness (i.e., reasonable, helpful), and high Self-transcendence (i.e., imaginative, intuitive) (Cloninger 2004). Although using the product also increases measurement error multiplicatively, the correlation between Creativity and Ln (LF/HF) is higher than the correlation of each character trait separately, supporting a nonlinear association of character with HRV. In contrast, being organized (high Self-directedness and Cooperativeness but low Self-transcendence) or being fanatical (high Self-directedness and Self-transcendence but low Cooperativeness) were not significantly associated with LF/HF. These results are presented in Table 1.

Table 2 presents relationships of other personality traits with the HRV variables included in the study. Openness is negatively correlated with many of the HRV variables, including those indicative of lower sympathetic activity (negative correlations with SDNN Index and ULF power) and those indicative of low parasympathetic activity (negative correlations with RMS-SD and Ln LF/HF). Low activity for both branches of the autonomic nervous system suggests that heart rate variability is only weakly regulated in people high in Openness, but parasympathetic regulation is relatively greater than sympathetic influences (i.e., correlation with Ln LF/HF is negative). In contrast, Physical Aggression was associated with high sympathetic activity (indicated by positive correlation with SDNN, SDNN Index, LF, and VLF power, and no significant correlation with RMS-SD) whereas Avoidant Attachment was associated with lower parasympathetic activity (indicated by negative correlations with RMS-SD and Ln LF/HF). Circadian regulation of HRV is also weak in people high in Openness (indicated by no significant correlation with ULF in 24 hour analysis), so the HRV observed in relation to Openness is really unregulated reactivity to transient stimuli combined with ease of relaxation when unchallenged. Not shown in Table 2, Agreeableness was correlated $\mathrm{r}=.199^{*}(p<.05)$ Ln (HF5), an indicator of high parasympathetic activity and Forgiveness was correlated with SDANN, an indicator of low sympathetic activity, $r=-.224$ ( $r$

Table 1.

Correlations between TCI traits and HRV measures.

\begin{tabular}{cc}
\hline TCI Traits & Ln (LF/HF) \\
\hline Self -Directedness & $-.199^{*}$ \\
Cooperativeness & $-.199^{*}$ \\
Self-Transcendence & $-.197^{*}$ \\
Creative & $-.277^{* *}$ \\
Organized & $\mathrm{Ns}$ \\
Fanatical & $\mathrm{Ns}$ \\
\hline
\end{tabular}

Note: ${ }^{*} p<.05 ;{ }^{* *} p<.01$; Creative = SD X CO X ST; Organized = SD X CO X (STmax-STscore); Fanatical = SD X (COmax-COscore) X ST. 
Table 2.

Correlations between openness, physical aggression, avoidant attachment and HRV measures.

\begin{tabular}{cccc}
\hline & Openness & Physical aggression & Avoidance \\
\hline SDNNI & $-.222^{*}$ & $.244^{*}$ & $\mathrm{~ns}$ \\
SDNN & $-.216^{*}$ & $.216^{*}$ & $\mathrm{~ns}$ \\
SDANN & $-.233^{*}$ & $\mathrm{~ns}$ & $\mathrm{~ns}$ \\
RMS-SD & $-.209^{*}$ & $\mathrm{~ns}$ & $-.234^{*}$ \\
Ln TP5 & $-.202^{*}$ & $.277^{* *}$ & $\mathrm{~ns}$ \\
Ln ULF24 & $-.247^{*}$ & $\mathrm{~ns}$ & $\mathrm{~ns}$ \\
Ln VLF5 & $-.217^{*}$ & $.254^{* *}$ & $\mathrm{~ns}$ \\
Ln LF5 & $\mathrm{ns}$ & $.322^{* *}$ & $\mathrm{~ns}$ \\
Ln HF5 & $\mathrm{ns}$ & $\mathrm{ns}$ & $-.328^{* *}$ \\
Ln LF/HF & $-.217^{*}$ & $.229^{*}$ & $.318^{* *}$ \\
\hline
\end{tabular}

Note: ${ }^{*} p<.05 ;{ }^{*} p<.01$.

$<.05)$.

Choosing just two of the HRV variables for further scrutiny, we conducted hierarchical linear regression with one dependent variable from the power spectrum analysis, specifically the natural log of the ratio of low frequency (sympathetic) component to the high frequency (parasympathetic) component (Ln $(\mathrm{LF} / \mathrm{HF})$ ), and also one dependent variable from the time domain analysis, specifically the SDNN Index, which is the mean of standard deviation of the RR intervals for all the 5 minute intervals of the 24-hour recording. We considered age as first block predictor and personality traits as second block predictors. The results are presented in Tables 3 and $\mathbf{4}$. In the Power Spectrum analysis, personality traits explained $23.1 \%$ of the variance in $\mathrm{Ln}(\mathrm{LF} / \mathrm{HF})$, being creative decreased the ratio whereas being forgiving, physically aggressive and being avoidantly attached increased the ratio, so that creativity was associated with greater vagal (parasympathetic) activity whereas the other variables had greater sympathetic activity and/or lower parasympathetic activity. In the Time domain analysis, personality traits explained $10.6 \%$ of the variance in the SDNN Index: being creative and being physically aggressive had greater HRV whereas being open had lower HRV on this indicator of sympathetic activity. Included in Tables $\mathbf{3}$ and $\mathbf{4}$ are the second models, those with personality traits entered after the first predictor age at time of measurement.

\section{Discussion}

The ratio $\mathrm{Ln}(\mathrm{LF} / \mathrm{HF})$ is of considerable psychological and physiological interest. It is considered a measure of balance between the excitatory action of the SNS and the inhibitory action of the PNS over the 24-hours. However, the interpretation of the associations found between personality traits and the ratio requires consideration of concomitant relations with indicators that can dissociate sympathetic and parasympathetic inputs. For example, high levels of sympathetic activity are indicated by high values for the time-domain variables of SDNN and SDNN Index and by the frequency domain variables of LF, VLF, which we observed to be positively correlated with self-reported Physical Aggression. On the other hand, high levels of parasympathetic activity are indicated by high values on the time-domain variable of RMS-SD (which was
Table 3.

Summary of hierarchical regression analysis for personality variables predicting the frequency domain variable Ln (LF/HF).

\begin{tabular}{cccc}
\hline & \multicolumn{3}{c}{ Model 2 } \\
\cline { 2 - 4 } Variable & $\mathrm{B}$ & SE B & $\beta$ \\
\hline Age & -.007 & .004 & -.161 \\
Creativity & .001 & .001 & $-.208^{*}$ \\
Forgiveness & .123 & .055 & $.219^{*}$ \\
Physical aggression & .224 & .094 & $.222^{*}$ \\
Avoidance & .115 & .040 & $.281^{* *}$ \\
R & & .234 & \\
F for change in $\mathrm{R}^{2}$ & & 6.34 & \\
\hline
\end{tabular}

Note: ${ }^{*} p<.05 ;{ }^{* *} p<.005$.

Table 4.

Summary of hierarchical regression analysis for predicting the time domain indicator of sympathetic influences on HRV, SDNNI total.

\begin{tabular}{crcc}
\hline & \multicolumn{3}{c}{ Model 2 } \\
\cline { 2 - 4 } Variable & \multicolumn{1}{c}{ B } & SE B & $\beta$ \\
\hline Age & -.127 & .174 & -.072 \\
Creativity & .001 & .001 & $.298^{* *}$ \\
Openness & -6.801 & 2.357 & $-.326^{* *}$ \\
Physical aggression & 7.556 & 3.294 & $.230^{* *}$ \\
$R^{2}$ & .108 & & \\
$F$ for change in $R^{2}$ & $3.78^{* * *}$ & & \\
\hline
\end{tabular}

Note: ${ }^{*} p<.05 ;{ }^{* *} p<.005$.

correlated negatively with Openness and with Avoidant Attachment) and the frequency-domain variable of HF (which was correlated positively with Agreeability and negatively with Avoidant attachment).

The present study found that being creative (the product of the three TCI character traits) was negatively associated with the $\mathrm{LF} / \mathrm{HF}$ ratio. A reasonable interpretation would be that more mature and developed character (Cloninger, Svrakic, \& Svrakic, 1997 ) is associated with more PNS inhibitory activity, as a form of mature emotional regulation that arises from an outlook of unity and connectedness with other people and one's surroundings (Cloninger, 2004; Cloninger et al., 2010; Cloninger, 2013). This finding of the relationship between creativity and high vagal tone indicates that an outlook of unity allows a person for function efficiently in a state of calm awareness without unhealthy psychophysiological arousal or defensiveness (Bradley et al., 2010; McCraty et al., 2009). In other words, people with a creative character configuration who are highly self-directed, cooperative, and self-transcendent can function well while remaining calm and happy in the face of the challenges of daily life (Cloninger, 2013). They are healthy because of their ability to let go rather than to defend themselves with aggression or avoidance ("fight or flight"). They are able to remain alert and think clearly by being calm and happy (Fredrickson and Losada 2005). Their physiological coherence promotes resilience and maintains health (Bradley et al., 2010; Cloninger et al., 2012; Cohn et al., 2009). Measures of HRV provide an objective set of indicators of this creative and coherent way of adapting to 
life challenges.

The finding that Creativity was characterized by a lower Ln (LF/HF) is noteworthy because other character profiles that include high Self-directedness were not associated with such autonomic activity. Creativity was measured as the synergistic strength that emerges from the combination of being Self-directed (i.e., resourceful and realistic), Cooperative (i.e., reasonable and helpful), and Self-transcendent (i.e., imaginative and intuitive). The other healthy character profile is being organized, that is, highly self-directed and cooperative, but not self-transcendent. Being organized was not significantly associated with autonomic balance, suggesting that self-transcendence is crucial for autonomic balance at least under the challenging conditions of rapid change we face in the world today (Cloninger, 2013). However, people who are high in Self-directedness and Self-transcendence but not Cooperativeness (i.e., hostile fanatics) are also not functioning in a state of cardiac coherence according to our observations. Therefore, it is the synergy between all three components of character measured by the TCI that is crucial for functioning with an outlook of unity and connectedness that includes respect for one's self, other people, and the world as a whole.

In contrast, Openness is negatively correlated with many of the HRV variables, including those indicative of lower sympathetic activity (negative correlations with SDNN Index and ULF) and those indicative of low parasympathetic activity (negative correlations with RMS-SD and Ln LF/HF). Low activity for both branches of the autonomic nervous system suggests that heart rate variability is only weakly regulated in people high in Openness, even though parasympathetic regulation is relatively greater than sympathetic influences (i.e., the correlation with $\mathrm{Ln}(\mathrm{LF} / \mathrm{HF})$ is negative). Circadian regulation of HRV is also weak in people high in Openness (indicated by no significant correlation with ULF in 24 hour analysis), so the HRV observed in relation to Openness is really unregulated reactivity to transient stimuli combined with ease of relaxation when unchallenged.

Physical Aggression was associated with high sympathetic activity (indicated by positive correlation with SDNN, SDNN Index, LF, VLF), but was not related to any differences in parasympathetic activity (indicated by no significant correlation with RMS-SD). In contrast, Avoidant Attachment was associated with low parasympathetic activity (indicated by negative correlations with RMS-SD and Ln (LF/HF)). On the other hand, Agreeableness was correlated with an indicator of high parasympathetic activity (positive correlation with HF) whereas Forgiveness was correlated with an indicator of lower sympathetic activity (negative correlation with SDANN).

Consequently, in the multiple regression analysis of autonomic balance measured by Ln (LF/HF), being creative decreased the ratio whereas being physically aggressive, avoidant, and/or simply forgiving increased the ratio. In other words, creative functioning, such as non-violent assertiveness, is characterized by greater vagal (parasympathetic) regulation to maintain autonomic balance whereas other personality variables depend on either greater sympathetic activity and/or lower parasympathetic activity. Creative problem-solving with a calm, happy outlook of unity is more integrative and adaptive than defensive responding (i.e., aggression or avoidance) or submissive responding (i.e., agreement or forgiveness).

In the multiple regression analysis of the SDNN Index, which is the mean of the standard deviation of the time interval between successive normal heart beats (i.e., the RR intervals) throughout the day, being creative or being physically aggressive contributed to greater HRV. In contrast, once creativity and physical aggression were taken into account, being open resulted in lower HRV, even though the SDNN Index is considered to indicate mostly sympathetic activity. This finding fits with the interpretation that openness is associated with weak regulation of cardiorespiratory reactivity: once the strong active influences of creative or aggressive responses are taken into consideration, openness is not associated with increased HRV.

The results presented here should be considered in the light of the study limitations. Self-report questionnaires are highly reliable but imperfect measures of personality. All personality measures have measurement error due to a variety of known causes as well as random effects (Schmidt \& Hunter, 1996). Because this is an exploratory study we used a wide range of personality instruments, and many of them did not associate systematically with HRV variables. The personality variables we reported on were those that had at least one two-tailed significant correlation at $p \leq .05$ with at least one of the HRV variables included in the analyses. Casting a wide net as we did, all results should be viewed as hypothesis-generating, rather than as conclusive.

In addition, the measurement of HRV is restricted in the study to 104 complete records. The measurement of HRV is highly reliable and ecologically valid because it is conducted over 24 hours and the analyses of the data were conducted by expert technicians and physiological psychologists. The interpretation of our results should be viewed with these reservations in mind.

The results of this study require replication. However, they sketch intriguing pathways through personality traits, emotional response, CNS action, and heart activity. The regulation of cardiorespiratory functioning through the autonomic nervous system may be an important way by which personality jointly influences the physical, mental, and social aspects of health and well-being.

\section{REFERENCES}

Ablonskytė-Dūdonienė, R., Bakšytė, G., Ceponienė, I., Kriščiukaitis, A., Drègūnas, K., \& Ereminiené, E. (2012). Impedance cardiography and HRV for long-term cardiovascular outcome prediction after MI. Medicina, 48, 350-358.

Al-Krenawi, A., Graham, J. R., \& Kanat-Maymon, Y. (2009). Analysis of trauma exposure, symptomatology and functioning in Jewish Israeli and Palestinian adolescents. The British Journal of Psychiatry, 195, 427-432. http://dx.doi.org/10.1192/bjp.bp.108.050393

Antelmi, I., de Paula, R. S., Shinzato, A. R., Peres, C. A., Mansur, A. J., \& Grupi, C. J. (2004). Influence of age, gender, body mass index, and functional capacity on heart rate variability in a cohort of subjects without heart disease. American Journal of Cardioliogy, 93, 381-385. http://dx.doi.org/10.1016/j.amjcard.2003.09.065

Araújo, F., Antelmi, I., Pereira, A. C., Latorre, M. R., Grupi, C. J., Krieger, J. E., \& Mansur, A. J. (2006), Lower heart rate variability is associated with higher serum high-sensitivity C-reactive protein concentration in healthy individuals aged 46 years or more. Internsl Journal of Cardiology, 107, 333-337. http://dx.doi.org/10.1016/j.ijcard.2005.03.044

Bagby, R. M., Parker, J. D. A., \& Taylor, G. J. (1994). The 20-item Toronto alexithymia scale-I. Item selection and cross-validation of the factor structure. Journal of Psychosomatic Research, 38, 23-32. http://dx.doi.org/10.1016/0022-3999(94)90005-1

Berry, J. W., Worthington, E. L., O’Connor, L. E., Parrott III, L., \& Wade, N. G. (2005). Forgivingness, vengeful rumination, and affec- 
tive traits. Journal of Personality, 73, 183-226.

http://dx.doi.org/10.1111/j.1467-6494.2004.00308.x

Bradley, R. T., McCraty, R., Atkinson, M., Tomasino, D., Daugherty, A., \& Arguelles, L. (2010). Emotion, self-regulation, psychophysiological coherence, and test anxiety: Results from an experiment using lectrophysiological measures. Applied sychophysiological Biofeedback, 35, 261-283. http://dx.doi.org/10.1007/s10484-010-9134-x

Buss, A. H., \& Perry, M. (1992). The aggression questionnaire. Journal of Personality and Social Psychology, 63, 452-459. http://dx.doi.org/10.1037/0022-3514.63.3.452

Caprara, G. V., Alessandri, G., Eisenberg, N., Kupfer, A., Steca, P., Caprara, M. G., Yamaguchi, S., Fukuzawa, A., \& Abela, J. (2012). The positivity scale. Psychological Assessment, 24, 701-712. http://dx.doi.org/10.1037/a0026681

Carney, R. M., Blumenthal, J. A., Stein, P. K., Watkins, L., Catellier, D., Berkman, L. F., Czajkowski, S. M., O’Connor, C., Stone, P. H., \& Freedland, K. E. (2001). Depression, heart rate variability, and acute myocardial infarction, Circulation, 104, 2024-2028. http://dx.doi.org/10.1161/hc4201.097834

Chapman, B. P., \& Goldberg, J. R. (2011). Replicability and 40-year predictive power of childhood ARC types. Journal of Personality and Social Psychology, 101, 593-606. http://dx.doi.org/10.1037/a0024289

Chapman, B. P., Fiscella, K., Kawachi, I., \& Duberstein, P. R. (2010). Personality, socioeconomic status, and all-cause mortality in the United States. American Journal of Epidemiology, 171, 83-92. http://dx.doi.org/10.1093/aje/kwp323

Cloninger, C. R. (2003). Completing the psychobiological architecture of human personality development: Temperament, character, and coherence. In U. M. Staudinger, \& U. E. R. Lindenberger (Eds.), Understanding human development: Dialogues with lifespan psychology (pp. 159-182). London: Kluwer Academic Publishers. http://dx.doi.org/10.1007/978-1-4615-0357-6_8

Cloninger, C. R. (2004). Feeling good: The science of well-being (p. 374). New York: Oxford University Press.

Cloninger, C. R. (2013). What makes people healthy, happy, and fulfilled in the face of current world challenges? Mens Sana Monographs, 11, 16-24. http://dx.doi.org/10.4103/0973-1229.109288

Cloninger, C. R., \& Zohar, A. H. (2011). Personality and the perception of health and happiness. Journal of Affective Disorders, 128, 24-32. http://dx.doi.org/10.1016/j.jad.2010.06.012

Cloninger, C. R., Salloum, I. M., \& Mezzich, J. E. (2012). The dynamic origins of positive health and wellbeing. International Journal of Person-Centered Medicine, 2, 1-9.

Cloninger, C. R., Svrakic, N. M., \& Svrakic, D. M. (1997). Role of personality self-organization in development of mental order and disorder. Development and Psychopathology, 9, 881-906. http://dx.doi.org/10.1017/S095457949700148X

Cloninger, C. R., Zohar, A. H., \& Cloninger, K. M. (2010). Promotion of well-being in person-centered mental health care. Focus, 8, 165179.

Cloninger, C. R., Zohar, A. H., Hirschmann, S., \& Dahan, D. (2012). The psychological costs and benefits of being highly persistent: Personality profiles distinguish mood disorders from anxiety disorders. Journal of Affective Disorders, 136, 758-766. http://dx.doi.org/10.1016/j.jad.2011.09.046

Cohn, M. A., Fredrickson, B. L., Brown, S. L., Mikels, J. A., \& Conway, A. M. (2009). Happiness unpacked: Positive emotions increase life satisfaction by building resilience. Emotion, 9, 361-368. http://dx.doi.org/10.1037/a0015952

Cole, S. W., Arevalo, J. M., Takahashi, R., Sloan, E. K., Lutgendorf, S. K., Sood, A. K., \& Seeman, T. E. (2010). Computational identification of gene-social environment interaction at the human IL6 locus. Proceedings of the National Academy of Sciences, 107, 5681-5686. http://dx.doi.org/10.1073/pnas.0911515107

Denollet, J. (2005). DS14: Standard assessment of negative affectivity, social inhibition, and type D personality. Psychosomatic Medicine, 67, 89-97. http://dx.doi.org/10.1097/01.psy.0000149256.81953.49

Drabant, E. M., Kuo, J. R., Ramel, W., Blechert, J., Edge, M. D., Cooper, J. R., Goldin, P. R., Hariri, A. R., \& Gross, J. J. (2011). Ex- periential, autonomic, and neural responses during threat anticipation vary as a function of threat intensity and neuroticism, Neuroimage, 55, 401-410. http://dx.doi.org/10.1016/j.neuroimage.2010.11.040

Edmonds, G. W. (2011). Personality and the healthy lifestyle (HLS) as predictor of physical health: Can the HLS be explained by personality? Doctoral Dissertation, Champaign: University of Illinois at Urbana.

Etzion, D., \& Laski, S. (1998). The big five inventory (version 5a). TelAviv: Tel-Aviv University.

Fredrickson, B. L. \& Losada, M. F. (2005). Positive affect and the complex dynamics of human flourishing. American Psychologist, 60, 678-686. http://dx.doi.org/10.1037/0003-066X.60.7.678

Grant, C. C., Vilijoen, M., van Rensburg, D. C., \& Wood, P. S. (2012). HRV assessment of the effect of training on autonomic cardiac control. Annals of Noninvasive Electrocardiology, 17, 219-229. http://dx.doi.org/10.1111/j.1542-474X.2012.00511.x

Hainsworth, R. (1995). The control and physiological importanceof heart rate. In M. Malik, \& A. J. Camm (Eds.), Heart rate variability (pp. 147-163). Armonk, NY: Futura Publishing Company, Inc.

Hintsanen, M., Pulkki-Råback, L., Juonala, M., Viikari, J. S., Raitakari, O. T., \& Keltikangas-Järvinen, L. (2009). Cloninger's temperament traits and preclinical atherosclerosis: The cardiovascular risk in young Finns study. Journal of Psychosomatic Research, 67, 77-84. http://dx.doi.org/10.1016/j.jpsychores.2009.01.002

Hiramura, H., Uji, M., Shikai, N., Chen, Z., Matsuoka, N., Kitamura, T. et al. (2010). Understanding externalizing behavior from children's personality and parenting characteristics. Psychiatry Research, 175, 142-147. http://dx.doi.org/10.1016/j.psychres.2005.07.041

Jarrin, D. C., McGrath, J. J., Giovanniello, S., Porier, P., \& Lambert, M. (2012). Measurement fidelity of HRV signal processing: The devil is in the details. International Journal of Psychophysiology, 86, 88-97. http://dx.doi.org/10.1016/j.ijpsycho.2012.07.004

Josefsson, K., Jokela, M., Cloninger, C. R., Hintsanen, M., Salo, J., Hinsta, T., Pulkki-Rabak, L., \& Keltikangas-Järvinen, L. (2013a) Maturity and change in personality: Developmental trends of temperament and character in adulthood. Development and Psychopathology, 25, 713-727. http://dx.doi.org/10.1017/S0954579413000126

Josefsson, K., Jokela, M., Hintsanen, M., Cloninger, C. R., PulkkiRabak, L., Merjonen, P., Hutri-Kahonen, N., \& Keltikangas-Järvinen, L. (2013b). Parental care-giving and home environment predicting offspring's temperament and character traits after 18 years. Psychiatry Research. http://dx.doi.org/10.1016/j.psychres.2013.01.007i

Kawachi, I., Sparrow, D., Vokonas, P. S., \& Weiss, S. T. (1995). Decreased heart rate variability in men with phobic anxiety (data from the normative aging study). American Journal of Cardiology, 75, 882-885. http://dx.doi.org/10.1016/S0002-9149(99)80680-8

Koelsch, S., Enge, J., \& Jentschke, S. (2012). Cardiac signatures of personality. PLOS ONE, 7, 1-9. http://dx.doi.org/10.1371/journal.pone.0031441

Kwako, L. E., Noll, J. G., Putnam, F. W., \& Trickett, P. K. (2010). Childhood sexual abuse and attachment: An intergenerational perspective. Clinical Child Psychology and Psychiatry, 15, 407-422. http://dx.doi.org/10.1177/1359104510367590

Lodi-Smith, J., Jackson, J., Bogg, T., Walton, K., Wood, D., Harms, P., \& Roberts, B. W. (2010). Mechanisms of health: Education and health-related behaviours partially mediate the relationship between Conscientiousness and self-reported physical health. Psychology and Health, 25, 305-319. http://dx.doi.org/10.1080/08870440902736964

Matsuoka, O., Otsuka, K., Murakami, S., Hotta, N., Yamanaka, G., Kubo, T., Yamanaka, M., Shinagawa, M., Nunoda, S., Nishimura, Y., Shibita, K., Saitoh, H., Nishinaga, M., Ishine, M., Wada, T., Okumiya, K., Matsubayashi, K., Yano, S., Ishihara, K., Cornelissen G., Halberg, F., \& Ozawa, T. (2005). Arterial stiffness independently predicts CVE in an elderly community-Longitudinal investigation for the LILAC study. Biomedical Pharmacotherapy, 59, S40-S44. http://dx.doi.org/10.1016/S0753-3322(05)80008-3

McCraty, R., \& Atkinson, M. (1996). Autonomic assessment report: A comprehensive heart rate variability analysis. In R. McCraty (ed.), Heart math research center reports. Boulder Creek, CA: Institute of 
Heart Math.

McCraty, R., Atkinson, M., Lipsenthal, L., \& Arguelles, L. (2009). New hope for correctional officers: An innovative program for reducing stress and health risks. Applied Psychophysiological Biofeedback, 34, 251-272. http://dx.doi.org/10.1007/s10484-009-9087-0

McCraty, R., Atkinson, M., Tomasino, D., Goelitz, J., \& Mayrovitz, H. N. (1999). The impact of an emotional self-management skills course on psychosocial functioning and autonomic recovery to stress in middle school children. Integrative Physiological and Behavioral Sciences, 34, 246-268. http://dx.doi.org/10.1007/BF02688693

Miller, G. E., Chen, E., \& Parker, K. J. (2011). Psychological stress in childhood and susceptibility to the chronic diseases of aging: Moving toward a model of behavioral and biological mechanisms. Psychological Bulletin, 137, 939-997. http://dx.doi.org/10.1037/a0024768

Radloff, L. S. (1977). The CES-D scale: A self-report depression scale for research in the general population. Applied Psychological Measurement, 1, 385-401. http://dx.doi.org/10.1177/014662167700100306

Raynor, D. A., \& Levine, H. (2009). Associations between the fivefactor model of personality and health behaviors among college students. Journal of American College Health, 58, 73-81.

http://dx.doi.org/10.3200/JACH.58.1.73-82

Rosenström, T., Jokela, M., Cloninger, C. R., Hintsanen, M., Juonala, M., Raitakari, O., Viikari, J., \& Keltikangas-Järvinen, L. (2012). Associations between dimensional personality measures and preclinical atherosclerosis: The cardiovascular risk in Young Finns study. Journal of Psychosomatic Research, 72, 336-343. http://dx.doi.org/10.1016/j.jpsychores.2012.02.003

Schmidt, F. L., \& Hunter, J. E. (1996). Measurement error in psychological research: Lessons from 26 research scenarios. Psychological Methods, 1, 199-223. http://dx.doi.org/10.1037/1082-989X.1.2.199

Seligman, M. E. P., Steen, T. A., Park, N., \& Peterson, C. (2005). Positive psychology progress: Empirical validation of interventions. American Psychologist, 60, 410-421. http://dx.doi.org/10.1037/0003-066X.60.5.410

Steger, M. F., Frazier, P., Oishi, S., \& Kaler, M. (2006). The meaning in life questionnaire: Assessing the presence of and search for meaning in life. Journal of Counseling Psychology, 53, 80-93. http://dx.doi.org/10.1037/0022-0167.53.1.80

Surtees, P. G., Wainwright, N. W. J., Pooley, K., A., Luben, R. N., Khaw, K.-T, Easton, D. F., \& Dunning, A. M. (2011). Life stress, emotional health, and mean telomere length in the EPIC-Norfolk population. Journal of Gerontology, 66A, 1152-1162. http://dx.doi.org/10.1093/gerona/glr112
Task force of the European Society of Cardiology, \& The North American Society of Pacing Electrophysiology (1996). HRV, standards of measurement, physiological interpretation, and clinical use. European Heart Journal, 17, 354-381. http://dx.doi.org/10.1093/oxfordjournals.eurheartj.a014868

Thayer, J. F., Ahs, F., Fredrikson, M., Sollers III, J. J., \& Wager, T. D. (2012). A meta-analysis of HRV and neuroimaging studies: Implications for HRV as a marker of stress and health. Neuroscience and Biobehavioral Reviews, 36, 747-756. http://dx.doi.org/10.1016/j.neubiorev.2011.11.009

Uliaszek, A. A., Zinbarg, R. E., Mineka, S., Craske, M. C., Griffith, J. W., Sutton, J. M., Epstein, A., \& Hammen, C. (2012). A longitudinal examination of stress generation in depressive and anxiety disorders. Journal of Abnormal Psychology, 121, 4-15. http://dx.doi.org/10.1037/a0025835

van de Bree, M. B. M., Przybeck, T. R., \& Cloninger, C. R. (2006). Diet and personality: Associations in a population-based sample. Appetite, 46, 177-188. http://dx.doi.org/10.1016/j.appet.2005.12.004

van Zuiden, M., Kavelaars, A., Rademaker, A. R., Vermetten, E., Heijnen, C. J., \& Geuze, E. (2011). A prospective study on personality and the cortisol awakening response to predict posttraumatic stress symptoms in response to military deployment. Journal of Psychiatric Research, 45, 713-719.

http://dx.doi.org/10.1016/j.jpsychires.2010.11.013

Voss, A. (2007). Longitudinal analysis of HRV. Journal of Electrocardiology, 40, 826-829. http://dx.doi.org/10.1016/j.jelectrocard.2006.10.024

Watson, D., Clark, L. A., \& Tellegen, A. (1988). Development and validation of brief measures of positive and negative affect: The PANAS scales. Journal of Personality and Social Psychology, 54, 1063-1070. http://dx.doi.org/10.1037/0022-3514.54.6.1063

Wei, M., Russell, D. W., Malinckrodt, B., \& Vogel, D. L. (2007). The experience in close relationship ECR-short form: Reliability, validity, and factor structure. Journal of Personality Assessment, 88, 187204. http://dx.doi.org/10.1080/00223890701268041

Zohar, A. H., \& Cloninger C. R. (2011). The psychometric properties of the TCI-140 in Hebrew. European Journal of Psychological Assessment, 27, 73-80. http://dx.doi.org/10.1027/1015-5759/a000046

Zohar, A. H., Denollet, J. K., Lev-Ari, L., \& Cloninger, C. R. (2011). The psychometric properties of the DS14 in Hebrew and the prevalence of type D in Israeli adults. European Journal of Psychological Assessment, 27, 274-281. http://dx.doi.org/10.1027/1015-5759/a000074 